\title{
Transition to adult clinics in youth living with HIV since birth
}

\author{
Mylène Fernet ${ }^{1 *}$, Marie-Eve Richard ${ }^{1}$, Joseph Josy Lévy ${ }^{1}$, Joanne Otis ${ }^{1}$, Lapointe Normand ${ }^{2}$, Samson Johanne ${ }^{2}$, \\ Guylaine Morin ${ }^{2}$, Kimberly Wong ${ }^{1}$, Jocelyne Thériault ${ }^{1}$, Germain Trottier ${ }^{3}$ \\ From $16^{\text {th }}$ International Symposium on HIV and Emerging Infectious Diseases \\ Marseille, France. 24-26 March 2010
}

\section{Background}

For youth living with HIV, transition from childhood to adulthood is also a transition from child to adult HIV health care clinics. Related studies show the more youth are spending time in pediatric services the more difficult the transition is likely to be. It appears many factors can facilitate or cause difficulties in the transition process; including individual factors and environmental factors. In this study we explore the transition process from child to adult HIV health care clinics through personal experiences of young adults infected by perinatal transmission.

\section{Methods}

Within a qualitative chronological (longitudinal) research framework, 18 youth aged from 13 to 22 years participated twice in individual semi-directed interviews within a three year interval at the Centre Maternel et Infantile sur le Sida du CHU Sainte-Justine in Montreal, Canada. At the second interview, 8 participants had gained their majority (18 years or more). Among those, 6 participants were then attending an adult HIV clinic and 2 had abandoned their medical followup.

\section{Results}

Youth for whom the medications remained meaningful three years later reported continuous trajectories in terms of treatment plan and medical follow-up. In contrast, youth with more troublesome relationships with the medication reported trajectories that were marked by setbacks: they underwent treatment changes involving heavier dosage regimens and more serious side effects, and in many cases they stopped treatment for significant lengths of time. They felt that taking medication was a daily reminder of their HIV status, which differentiated them from their peers. In addition to the meaning attributed to their treatment, relations with caregivers tend to play an important role in the clinical transition process. Youth who reported good treatment adherence and uninterrupted follow up described the same trusting relationship and closeness with their new physician and health care team.

\section{Discussion}

Particular attention should be paid to youth encountering difficulties of adherence during their critical transition period to adult clinics. Interventions aimed at helping youth through the transition process should focus on the meaning attributed to their medical follow up and allow them to explore affective issues along their journey.

\section{Author details}

${ }^{1}$ Université du Québec à Montréal, Montréal, Canada. ${ }^{2} \mathrm{CHU}$ Ste-Justine, Université de Montréal, Montréal, Canada. ${ }^{3}$ Université Laval, Québec, Canada.

Published: 11 May 2010

doi:10.1186/1742-4690-7-S1-P116

Cite this article as: Fernet et al.: Transition to adult clinics in youth living with HIV since birth. Retrovirology 2010 7(Suppl 1):P116.

\footnotetext{
* Correspondence: fernet.mylene@uqam.ca

${ }^{1}$ Université du Québec à Montréal, Montréal, Canada
} 